\title{
0 anônimo excludente: experimentações do corpo-subjetividade de uma mulher negra em um ambiente digital de anonimato
}

\author{
The excluding anonymous: experiments of a black woman's body- \\ subjectivity in a digital environment of anonymity
}

\section{Pollyane Belo}

Mestranda do Programa de Pós-Graduação em Comunicação da Universidade Federal Fluminense.

\section{Mayka Castellano}

Professora do Programa de Pós-Graduação em Comunicação e do Departamento de Estudos Culturais e Mídia da Universidade Federal Fluminense.

\section{RESUMO}

Este artigo se propõe a pensar as reações e afecções sofridas por uma mulher negra brasileira em um chat anônimo internacional que omite qualquer tipo de marcação identitária a priori. Identificamos que o auge da perturbação das trocas de mensagens foi o momento do desvelamento da raça e/ou da nacionalidade da sujeita. A partir daí, a subjetividade por trás da tela do computador foi assimilada e correlacionada pelos seus interlocutores a uma corporalidade negra e/ou brasileira, e, desta compreensão, eclodiram diversas relações de poder e respostas heterogêneas, que este trabalho analisa.

Pallavras-chave: Mulher negra; Anonimato; Racismo. 


\section{ABSTRACT}

This article proposes a reflection on the reactions and affections suffered by a black Brazilian woman in an anonymous international chatroom that omits any kind of $a$ priori identity marker. We identified that the peak of disturbance in the message exchange was the moment of the unveiling of the race and/or nationality of the subject. From there, the subjectivity behind the computer screen was assimilated and correlated by its interlocutors with a black and/or Brazilian corporality, and from this understanding, diverse power relations and heterogeneous responses emerged, which this work analyzes.

Keywords: Black woman; Anonymity; Racism.

\section{RESUMEN}

Este artículo se propone a pensar las reacciones y afecciones sufridas por una mujer negra brasileña en un chat anónimo internacional que omite cualquier tipo de marcación identitaria a priori. Identificamos que el auge de la perturbación de los intercambios de mensajes fue el momento del desvelamiento de la raza y/o de la nacionalidad de la sujeta. A partir de ahí, la subjetividad detrás de la pantalla fue asimilada y correlacionada por sus interlocutores a una corporalidad negra y/o brasileña, $y$, de esta comprensión, eclosionaron diversas relaciones de poder y respuestas heterogéneas, que este trabajo analiza.

Pallabras-clave: Mujer negra. Anonimato. Racismo.

\section{Introdução}

Neste artigo, buscamos refletir sobre a materialização do racismo e do sexismo em ambientes virtuais. 0 questionamento básico do trabalho pode ser formulado do seguinte modo: "quais são as possibilidades de existência em um mundo que abdica da pluralidade de sujeitos?". Com essa pergunta em mente, recorremos a um artifício propício a interações sem imagens ou qualquer tipo de identificação dos indivíduos envolvidos: o website Omegle, dispositivo que atua como mediador de interações de pessoas em um ambiente de anonimato completo.

Lançada há oito anos, a plataforma possui o modo de interação text que não exige nenhum tipo de informação prévia; não há nicknames (apelidos), fotos de identificação ou qualquer tipo de login para conversar com um desconhecido. 0 anonimato 
encontrado no "submundo" das ferramentas de sociabilidade virtual subsome e transforma o questionamento primário - "quais são as possibilidades de existência dentro de um ambiente anônimo (que abdica da pluralidade de sujeitos)?". É importante lembrar que essa experimentação de si contém um elemento importante na sua diferenciação das outras baseadas no mundo "real": ela está cerceada pela intervenção de um indivíduo externo e anônimo que influenciará no processo de subjetivação desse $e u$.

Tal ideia veio à tona em um diálogo travado informalmente, durante um almoço de uma das autoras com a personagem do experimento que serve de objeto a este $\operatorname{artigo}^{3}$, já familiarizada com o website e seus obscuros interlocutores. 0 incômodo fulcral explicitado por ela na ocasião, a respeito desse espaço, devia-se ao alto retorno negativo que a mesma sofria ao revelar dois marcadores sociais de opressão que atuam sobre seu corpo: sua raça, negra, e sua localidade geográfica-cultural, o Brasil.

A partir do relato oferecido por nossa informante e pela observação de sua atuação no site 0 megle ${ }^{4}$, desejamos explicitar a maquinaria do racismo, em um lócus bastante oportuno para as pesquisas do campo da Comunicação. Apresentamos, nos próximos tópicos, os cerzimentos dos encontros travados entre uma das pesquisadoras que assinam este artigo, a sujeita protagonista de nosso relato, e tantos outros anônimos cujas reminiscências se consolidam aqui.

\section{o chat online}

Para a construção deste texto, adotamos um sistema de observação em que a pesquisadora contemplava as conversas da voluntária-participante (ou sujeita da pesquisa) no website. Quatro sessões, de no máximo uma hora cada, foram realizadas

\footnotetext{
${ }^{3} \mathrm{O}$ nome da sujeita voluntária-participante desta pesquisa foi omitido a pedido da própria.

${ }^{4} \mathrm{O}$ artigo, portanto, utiliza como corpus empírico a experiência de uma mulher brasileira e negra no site em questão, relatado e compartilhado com uma das autoras do trabalho. Cabe explicitar que as duas autoras que assinam o artigo são brancas.

${ }^{5}$ Os termos que indicarem o parceiro da conversa neste artigo sempre serão apresentados no gênero masculino, pois durante a pesquisa todas as conversas com extratos substanciais tiveram como interlocutores indivíduos que explicitaram o próprio gênero como "masculino".
} 
entre os meses de novembro e dezembro de 2017. 0 sistema oferece três formas de interação. A primeira é o videochat; nesta opção, o usuário compartilha imagens e sons por meio da sua webcam e microfone, além de poder escrever textos no lado direito da tela. A segunda é o modo spy, no qual o usuário formula uma pergunta que será atribuída a uma conversação entre dois outros indivíduos, em que o primeiro não poderá interceder, apenas espionar. A última possibilidade de diálogo se traduz na opção text; nesta, as trocas imagética e sonora desaparecem, permanecendo apenas a caixa de texto para a comunicação entre dois usuários. Os dois primeiros modos de interação foram excluídos da análise e o último ocupou o ponto central de observação nesta pesquisa.

Não foram implementados questionários pré-formatados ou entrevistas,. As interações com os usuários anônimos ${ }^{5}$ foram interpretadas e replicadas apenas a partir da observação dos diálogos travados. O diálogo virtual foi mantido pelo tempo que o parceiro de conversa desejou, conferindo a decisão de interrupção da conversa para o mesmo. Isto significa que a voluntária-participante manteve sua presença nas argumentações até o momento em que a outra parte decidisse desconectar do chat.

Apenas uma peça do diálogo foi previamente posta como inflexível dentro deste jogo randômico ${ }^{6}$ : quando questionada, ou quando achasse propício, a usuária deveria despejar quatro dados sobre si: 36, $f$, Brazil, black. As três primeiras informações derivam de uma pergunta que aparece amiúde e prematuramente nas conversas do Omegle: asl? Os termos corretos aplicáveis às siglas são age (idade), sex (gênero), location (localização). Perante às siglas inquisidoras, desvenda-se os três aspectos concedidos anteriormente: 36 (anos), $f$ (female, ou, gênero feminino), Brazil (Brasil). Não há, portanto, uma descrição mais detalhada, algo deliberadamente ocultado, no

\footnotetext{
5 Os termos que indicarem o parceiro da conversa neste artigo sempre serão apresentados no gênero masculino, pois durante a pesquisa todas as conversas com extratos substanciais tiveram como interlocutores indivíduos que explicitaram o próprio gênero como "masculino".

6 Dasmaceno (2013), ao analisar os relacionamentos no Omegle pelo prisma da sociabilidade, apoiado em Alfred Schutz e sua Fenomenolgia e Relações sociais (1979), confere certa jogabilidade motivada pela característica randômica do site. 0 usuário, para Dasmaceno, é sempre compelido a ir para outra conversa, procurar uma nova parelha, impulsionado pelo prazer do próprio jogo.
} 
intuito de ampliar as possibilidades para a imaginação do parceiro, fato que será alvo de reflexão no terceiro segmento deste artigo.

Além das informações básicas decididas previamente, foi necessário aplicar certo direcionamento para o pareamento de parceiros. 0 site de chats online oferece uma escolha de idiomas antes do início da conversação; dessa forma, o pareamento se converte entre pessoas que escolheram a mesma opção dentre as línguas disponíveis. Em um primeiro momento, o idioma escolhido foi o português; após algumas conexões, entretanto, percebemos que os pares começaram a se repetir. A partir daí, foi escolhido o inglês, idioma conhecido por nossa voluntária7. A alternativa não impediu a associação com um parceiro que se identificou como brasileiro, e, logo após a revelação, o idioma das mensagens se converteu para a língua portuguesa.

Um segundo e último tipo de filtragem para além da definição do idioma foi empregado para descartar parceiros não-humanos. Isso foi necessário visto que o site sofre com a confluência de bots, softwares desenvolvidos para simular sistematicamente ações humanas. Esses interlocutores-robô manifestaram-se continuamente nos pareamentos, inviabilizando qualquer tipo de troca subjetiva de fato. A identificação dos mesmos foi facilmente realizada, posto que as mensagens enviadas pelos bots voltavam-se para divulgação de conteúdos da web 2.0, como, por exemplo, outros sites que possuem serviços de chat online, ou links com promessas de mulheres nuas se exibindo para webcams. Dessa forma, o filtro se deu no descarte das interações com bots e apenas as interações com humanos foram contabilizadas e analisadas.

Sem reconhecimento ou identificação, a voluntária, ao clicar no modo text e iniciar o processo, aciona a janela para o chat. Dentro deste, é identificada como "You" (você) e o interlocutor como "Stranger" (estranho). 31 conexões se sucederam, das

\footnotetext{
${ }^{7}$ Ao assumirmos o inglês como a língua mais falada no mundo, acabamos por reforçar a existência uma bolha que se torna ainda mais perceptível nas dinâmicas dos sites de redes sociais e congêneres. 0 apartheid tecnológico combinado ao linguístico abrange a nova cartografia terrestre de inclusão de uma pequena parte com acesso ao desenvolvimento tecnológico e financeiro e a exclusão de um grande grupo, cada vez mais pobre e isolado desses avanços. Para mais informações sobre esta estrutura, ver os estudos de Sibilia (2016).
} 
quais 12 sofreram uma desconexão imediata ou o contato não obteve nenhuma troca de qualquer tipo de informação pessoal. Seis strangers operaram cortes da continuidade das conversas após receberem a informação black e cinco abandonos aconteceram após a informação Brazil ${ }^{8}$.

Estes comportamentos engendraram a hipótese de que uma mulher negra brasileira não se enquadra no imaginário desses homens como potencial interlocutora, independentemente de suas distintas intencionalidades na conversa. Perante estes interlocutores, a sujeita não atinge o perfil necessário para trocar peculiaridades em um diálogo virtual sem intermediações de imagens ou qualquer tipo de identificação latente. Dessa constatação surgiu uma inquietude: qual corporalidade pode ocupar o papel no imaginário dos strangers que desconectaram? Se não-negra, qual seria?

\section{Espaço Vazio}

Alguns interlocutores encontrados nessas experimentações silenciaram diante do labirinto que a corporalidade reduzida a $36, f$, Brazil suscita ao ser anunciada. Isto é, estes indivíduos mostraram um desinteresse por um detalhamento mais específico da corporalidade desta mulher anônima. Nesta seção abordaremos o silêncio que precede a exposição da raça e a falta de imediata curiosidade do outro por sua interlocutora após as informações básicas serem conferidas à conversa.

A ausência de questionamento sobre a etnia da sujeita nas conversas travadas se instaura desde as primeiras inquirições da interação. Não há um e relativo a ethnicity (etnicidade), ou $r$ relativo a race (raça), acoplado às siglas do asl. A falta de curiosidade sobre a cor da voluntária nos fez refletir sobre a suspeita de uma indiferença dos

\footnotetext{
${ }^{8}$ É necessário pontuar que cinco conexões fora dessas duas lógicas tiveram um destino peculiar. Duas interações foram interrompidas pelos parceiros quando a voluntária recusou migrar a conversação para o aplicativo de celular Snapchat e outras duas foram finalizadas após a renúncia da mesma em divulgar seu Facebook pessoal. Uma interação foi abertamente iniciada com uma sugestão de zoofilia, que a sujeita efusivamente rechaçou, desconectando assim que compreendeu a mensagem. Esta foi a única vez que houve desconexão por parte da voluntária. Nenhuma dessas interações receberam a informação sobre cor ou localidade; dessa forma, não foi possível mensurar a reação dos parceiros a partir destes dados.
} 
interlocutores atrelada à vontade de não abandonar as imagem individuais que cada um possui sobre o signo mulher. Assumindo uma multiplicidade de parceiros nas conversas, e resguardando suas singularidades, consideramos que a mulher conjecturada por cada indivíduo se atualiza de maneira particular; contudo, acreditamos que suas imagens se alimentam de uma mesma matriz simbólica.

Um diálogo travado no dispositivo Omegle traz reflexões sobre a relevância da corporeidade imaginada pelo outro neste ambiente, além da base comum imaginada do signo mulher. 0 parceiro que se apresentou como 28, $m$, London (28 anos, gênero masculino, Londres), ao ser indagado sobre a sua intencionalidade no site, exprimiu o seguinte motivo: "i'm looking for a cute girl" ("estou procurando por uma garota fofa"). Diante desta resposta seguiu-se a troca abaixo:

You: why does it matter if she's cute if you can't see her?

Stranger: Ha it's a good question

Stranger: It makes no difference

You: so, why you look for a cute girl on a website that you can't see anyone?

Stranger: I wish I had a good answer to that!

Stranger: But I don't

Stranger: It's just a line

Stranger: You got me!

You: answer the first thing that comes into your head

Stranger: About what?

You: about why appearance matters even when you don't have visual contact

Stranger: Because we use our imagination to build a picture of the other person $^{9}$

${ }^{9}$ Você: Por que importa que ela seja fofa se você não pode vê-la?/ Estranho: Ha é uma boa pergunta. Não faz diferença nenhuma. / Você: então, por que você procura por uma garota fofa em um website em que não pode ver ninguém? / Estranho: Gostaria de ter uma boa resposta para isso! Mas não tenho. É apenas uma expressão. Você me pegou! / Você: responda a primeira coisa que vier à sua mente. / Estranho: Sobre o quê??/ 
“Porque nós usamos nossa imaginação para construir uma imagem da outra pessoa". A condensação dessa afirmação é atravessada de uma intensidade que ao primeiro olhar pode soar como banal. Contudo, nessa simples frase podem estar contidas violências simbólicas balizadas por aquilo que cada um considera inimaginável. Para refletir sobre esse fato, pensemos na metodologia arqueológica foucaultiana (2008): como se dá a imaginação no Omegle? De cunho muito amplo, este questionamento ainda não é suficiente, distendendo-se para: a imaginação na plataforma seria moldada pela intenção dos usuários envolvidos? Se sim, observemos o exemplo de 28, m, London: quais signos "fofos" orbitam na mente deste interlocutor diante da sucinta tríade de dados apresentada no início da conversa pela sujeita? Qual tipo de corpo aparece na imaginação do interlocutor ao combinar as informações dadas com a sua intencionalidade?

Para fins de análise, é pertinente expor o desfecho da conversa com $28, m$, London. Após saber que 36, f, Brazil era negra, o indivíduo desconectou da conversa. Excluindo os diversos empecilhos triviais que poderiam ter motivado a desconexão, a coincidência do usuário sair do chat dois segundos após obter a informação da cor de pele da sujeita não pode passar despercebida. Ignorar a sua evasão-relâmpago seria uma atitude cínica em relação ao fazer desta pesquisa. A fuga aos fatos pode ser lida como uma demonstração de que no imaginário deste parceiro uma mulher negra não pode ocupar o local de uma garota fofa. Isso significa que sua matriz simbólica relativa à fofura feminina, que sobretudo na língua inglesa guarda uma conexão com a ideia de graciosidade, não comporta a ideia de pele negra; suas referências alimentam-se de uma ideologia excludente de determinada raça.

Insistimos em dois aspectos ainda neste exemplo. 0 interlocutor ainda vê a voluntária de 36 anos como uma "garota": afinal, o mesmo não se desligou da conversa após saber sua idade e, logo depois, confidenciou sua intenção na conversa, considerando a possibilidade de ter encontrado seu objeto de desejo. Esse fato reafirma a questão da infantilização da mulher engendrada pelo termo "garota", ou "menina".

Você: sobre o porquê a aparência importa quando você não tem contato visual / Estranho: Porque nós usamos a nossa imaginação para construir uma imagem da outra pessoa (tradução livre). 
Associado ao tema anterior, podemos concluir que, para além disso, a mulher-garota, para ser fofa-infantil, precisa ser não-negra.

O silêncio sobre a questão racial que precede a sentença I'm black ("Eu sou negra") evidencia a sintetização da corporalidade, sintetização que abarca um invólucro convenientemente não-negro, projetado pelo interlocutor sobre a sujeita. A zona de conforto da matriz simbólica nesse caso pode ser renomeada como "zona do imaginário não-negro", e seus construtos, que correm pelo lastro dos discursos homogeneizantes, são as bases sólidas para as restrições imaginárias de 28, m, London sobre 36, f, Brazil, que, decepcionado pelo imprevisível, abandona a conversa. As idealizações rasas construídas por cima de três pilares identitários genéricos implicam no movimento comum entre dois eixos: ora na assunção de uma mulher não-negra na outra ponta da conexão; ora o enquadramento estereotipante de uma homogenia da raça atravessada pela "brasilidade" dos corpos comercialmente turísticos vendidos para o resto do mundo.

\section{0 extrato da "brasilidade" dos corpos comerciáveis}

Outro excerto desta experiência se volta para o quesito "brasilidade" e a estereotipação dos corpos femininos brasileiros. 0 interlocutor neste exemplo identificou-se como 21, $m$, USA e posteriormente como white (caucasiano ou branco). Os dados $f$, Brazil foram apresentados juntos e não obtiveram resposta imediata, porém quando a idade (36) foi exprimida, uma única palavra foi despejada na tela do chat pelo parceiro: "hot" (sexy). No início da interação, o interlocutor sugeriu o roleplay, ou seja, um "faz-de-conta" sexual que designa papéis para as duas partes e a partir do qual uma trama erótica será construída pelos dois participantes. Apresento abaixo o fragmento do momento exato da proposta:

Stranger: looking to roleplay?

Stranger: USA

You: yeah, why not? 
You: what do you look like?

Stranger: I'm dark brown hair, brown eyes, 5'9, big chest and shoulders

You: i'm 5,7, big black hair, black eyes, dark skin

Stranger: wow that is sexy

Stranger: I'm white just let you know

You: yeah, i'm black

Stranger: $\mathrm{mmm}$ so any roles you want?

You: you tell me

Stranger: well stepmom/son, neighbors, best friend's mom or spoiled $\mathrm{brat} /$ maid $^{10}$

You: tell me your favorite

You: one that fit us

Stranger: spoiled brat/maid :\$

You: is that because my appearance fit the role of maid?

Stranger: mmm a bit, but also because I loves maids

Stranger: unless you like the fact I picked because your brazilian ;) ${ }^{11}$

A descrição do próprio corpo que a sujeita dá ao seu parceiro de conversa é sintética e superficial. Não menciona detalhes de sua conjuntura corporal, como o tamanho dos quadris, a espessura das suas coxas ou a circunferência de seu busto, mesmo assim a reação colhida é "wow that is sexy". Mais adiante, encontramos uma curiosa escolha dos papéis para o roleplay. 0 usuário opta por ser um menino

10 Madrasta/filho, vizinhos, mãe do melhor amigo ou menino teimoso/empregada doméstica são tipos de papéis que cada participante ocupará no roleplay. Neste caso, quando há uma discriminação de papéis generificados dentre as sugestões de roleplay, esses serão automaticamente assignados para as partes masculina e feminina da conversa. Por exemplo, a sujeita seria a mãe do melhor amigo do parceiro, pressupondo uma diferença de idade conveniente às idades reais aos integrantes da conversa.

${ }^{11}$ Estranho: procurando por roleplay? EUA. / Você: sim. qual a sua aparência? / Estranho: eu tenho cabelos castanhos escuros, olhos castanhos, 1,80 cm de altura, peito e ombros largos./Você: Eu tenho 1,74 de altura, cabelos longos e pretos, olhos pretos, pele escura. / Estranho: uau, sexy. eu sou branco, só pra você saber. / Você: é, eu sou negra. / Estranho: mmm então tem preferência por algum papel? / Você: você decide. / Estranho: bem madrasta/filho, vizinhos, mãe do melhor amigo ou menino teimoso/empregada doméstica. / Você: me diga o seu favorito. um que seja apropriado para nós. / Estranho: menino teimoso (pirralho)/empregada doméstica :\$. / Você: É por causa da minha aparência que se encaixa no papel de empregada doméstica? / Estranho: $\mathrm{mmm}$ um pouco, mas também porque eu amo empregadas domésticas. a não ser que você goste do fato de eu ter escolhido porque você é brasileira ;) (tradução livre). 
teimoso/pirralho enquanto ela seria uma empregada doméstica, provavelmente a serviço da casa do primeiro. Ao ser perguntado se a designação estaria associada com a cor de pele da parceira, o interlocutor responde "mmm um pouco, mas também porque eu amo empregadas domésticas / a não ser que você goste do fato de eu ter escolhido porque você é brasileira ;)".

O evidente nessa declaração é a correlação feita entre a subserviência do papel de uma empregada doméstica atrelado a um jogo erótico e a nacionalidade brasileira. Apesar da finalidade dessa pesquisa não ser qualificar moralmente ou analisar as condições psicológicas do desejo e dos fetiches, ainda assim há uma vontade de elucidação dos sentidos simbólicos que são escolhidos para protagonizar os desejos, constituintes da designação desses papéis. Ou melhor, investiga-se aqui o porquê das atualizações do desejo referirem-se a estereótipos de determinados indivíduos.

Com a cor e nacionalidade reveladas, as reações particulares foram analisadas de forma pormenorizada. Os movimentos imagéticos de desejo desses sujeitos, seus atos de designação de uma nacionalidade e raça ao servilismo erotizado e a recusa da fofura no corpo de uma mulher negra precisam ser compreendidos dentro de um quadro geral ligado à produção de subjetividade. Retornemos, então, às raízes dessas relações.

\section{Corpo-subjetividade moderna/colonial de gênero}

As relações, mesmo que efêmeras, entre as duas partes das interações travadas no Omegle devem ser levadas em consideração a partir de suas configurações. Invoco o diagnóstico de Foucault sobre as relações humanas para pensá-las: "toda relação humana é, a um certo grau, uma relação de poder. Nós evoluímos num mundo de relações estratégicas perpétuas. Qualquer relação de poder não é má em si mesma, mas isto é um fato que comporta sempre perigos" (Foucault 2001, p. 1193, tradução nossa). Os diálogos aqui explicitados denotam estes perigos subsequentes das dinâmicas do trato do poder e, se empregado de forma despótica, o poder configura-se em opressão. 
O contexto do mundo concreto concede material suficiente para a percepção das variáveis comportamentais do poder e como elas atuam nas fendas entre as diferentes individualidades, e simultaneamente, em suas intersecções. Raça/etnia, classe, gênero, desejo sexual, geração e localização são designações linguisticamente talhadas sobre materialidades, que, por sua vez, são influenciadas por sobreposições de poder fundadas em uma cultura dominante. As imposições dos autodefinidos centros colonizadores às suas designadas margens colonizadas se encontram nas articulações do poder na vida cotidiana e nos traços dessas efêmeras conversações virtuais. Como pontuou Foucault (2001), esses traços podem comportar perigos que emergem nos enfrentamentos, identificáveis nas reações dos usuários mencionados, frutos das preconcepções localizadas no vácuo de sentido entre as vírgulas de 36 , $f$, Brazil que os parceiros de conversa preencheram a partir de suas referências.

Os tratamentos à nossa sujeita surgem como rastros da urdidura do poder sobre determinada corporalidade e subjetividade. Da necessidade de explicitar as pressões de poder sobre os corpos, mesmo que imaginados em sua virtualidade, uma digressão genealógica deve ser levada em conta. Em Colonialidad del poder, eurocentrismo y América Latina ${ }^{12}$ (2000), Aníbal Quijano identifica a ideia de raça como um dos eixos mantenedores do padrão de poder mundial sobre os indivíduos, cuja construção se deu abaixo das vigas da colonização dos outros continentes pela Europa. Para Quijano (2000), a máquina colonialista dos séculos escravistas era movimentada por engrenagens comandadas pelo saber moderno e eurocêntrico.

A modernidade e seu ideário criado pelos europeus foi fundamental na tomada de terras, indivíduos e culturas durante o processo "civilizatório". Os preceitos modernos foram produzidos pela Europa e, ao mesmo tempo, metamorfoseados em uma narrativa em que a própria se designou protagonista. Dessa forma, as concepções eurocêntricas formaram uma potente tríade de delineamento das subjetividades e dos corpos: o saber/poder/existir foram lidos e (re)estruturados por lentes modernas e

\footnotetext{
${ }^{12}$ Colonialidade do poder, eurocentrismo e América Latina.
} 
coloniais, e as hastes divergentes das fôrmas impostas deveriam ser dominadas e/ou ceifadas.

O principal ponto a ser resgatado nessa trama de poder é o êxito da narrativa europeia, que atribuía a si mesma o estado mais avançado e longínquo do temido estado de natureza. Se os europeus eram os mais desenvolvidos da espécie humana, e sua simbologia exaltada como tal, a partir de uma dicotomia presumida não é difícil imaginar que todos os outros povos eram considerados inferiores em relação a eles. Os europeus carregaram o mérito de serem os únicos portadores do artefato mais inovador do momento, a modernidade, difundindo e sedimentando sua narrativa hegemonicamente em um novo panorama do padrão mundial de poder.

\begin{abstract}
Com efeito, todas as experiências, histórias, recursos e produtos culturais [...] acabaram sendo articulados em uma única ordem cultural global ao redor da hegemonia europeia ou ocidental. Em outras palavras, como parte do novo padrão do poder mundial, a Europa também concentrou sob sua hegemonia o controle de todas as formas de controle da subjetividade, da cultura e, sobretudo, do conhecimento, da produção do conhecimento. No processo que levou a esse resultado, os colonizadores exerceram diversas operações que dão conta das condições que levaram à configuração de um novo universo de relações intersubjetivas de dominação entre Europa e o europeu e as demais regiões e outras e populações do mundo, às quais estavam sendo atribuídas, no mesmo processo, novas identidades geoculturais. (Quijano, 2000b, p.209, tradução nossa).
\end{abstract}

Com a concepção da "razão humana", segregar sujeitos em hierarquias tornou-se uma conveniência da colonização. Os indivíduos das colônias foram historicamente diferenciados entre binarismos redutores, como primitivo e civilizado, tradicional e moderno, superior e inferior, racional e irracional, negro/índio ${ }^{13}$ e branco. Dessa forma, as dicotomias tornaram-se prerrogativas para classificar os colonizados para os propósitos capitalistas de seus colonizadores, justificando explorações escravagistas através de categorizações relativas a subculturas iletradas, privações de suas heranças intelecto-culturais, além do aniquilamento de populações inteiras.

${ }^{13}$ No caso do continente africano e das Américas. Posteriormente, as demais raças colonizadas também entraram nesta classificação binarizante. 
Com o apoio dos dualismos, a alteridade radical dos povos dominados ficou circunscrita em uma classificação ficcional moderna, ou seja, o conceito de "raça" e das novas identidades geoculturais configurou-se como a espinha dorsal da dominação dos países europeus sobre as regiões que os mesmos subalternizaram. As populações assignadas como os outros sofreram um processo de re-identificação histórica para se encaixar no "sistema-mundo" introduzido (Quijano, 2000b, p. 209). A heterogenia das subjetividades locais subsumiram-se em uma subjetividade hegemônica, que apontava para um único centro de cálculo latouriano ${ }^{14}$ : o europeu.

A produção do conhecimento acionada pelas subjetividade locais, ao se articular com um molde cerceado por uma imaginário hegemônico cria um cenário complexo. Quijano observou esta dinâmica e nomeou como colonialidade de poder o insumo deste padrão mundial de poder que se arrasta até os dias atuais.

Maria Lugones, ao rever o trabalho de Quijano, sublinha os atravessamentos específicos de uma corporalidade feminina. A filósofa analisa o fato de opressões múltiplas atuarem sobre os corpos das mulheres, algo que a mesma nomeia como "marcas potentes de dominação". Lugones volta-se para as mulheres não brancas e as violências que as mesmas podem sofrer em um sistema de colonialidade de poder, e que neste contexto caracteriza-se em uma colonialidade de gênero. Ou seja, a filósofa joga luz não somente sobre a categoria mental da modernidade, a "raça", mas também sobre a ficção binária chamada de "masculino" e "feminino" e sobre como Quijano "não tomou consciência sobre sua própria aceitação do significado hegemônico de gênero" (Lugones, 2008, p.78, tradução nossa). Como Lugones enfatiza,

a "colonialidade" não se refere apenas à classificação racial. É um fenômeno abrangente, uma vez que se trata de um dos eixos do sistema de poder e, como tal, permeia todo controle de acesso sexual, da autoridade coletiva, do trabalho, da subjetividade/intersubjetividade, e da produção de conhecimento a partir

14 O centro de cálculo de Bruno Latour (2004) refere-se a uma rede de simbologias agregadas em uma matriz de informação. Esta matriz cria veículos para colher os símbolos de seus estados naturais e deslocá-los para o centro de cálculo, possibilitando sua contemplação e ressignificação em seu novo local de existência. Para exemplificar, imagine os nativos das terras colonizadas sendo estudados por mentes europeias. 0 deslocamento da ideia de um ser não-branco a partir da perspectiva do europeu ressignifica esses seres, resultando no conceito de outras raças e centralizando as metodologias europeias como as principais formas de se entender o mundo. 
do próprio interior dessas relações intersubjetivas. Em outras palavras, todo o controle do sexo, subjetividade, autoridade e trabalho são expressos em conexão com a colonialidade (Lugones, 2008, p.79, tradução nossa).

Para a filósofa, há uma indissociabilidade nos locais onde a opressão atua sobre a singularidade dos corpos femininos com entrecruzamentos de racialização, generificação e imposição de classe social. As marcas potentes de dominação atuariam de tal forma que todas elas reduzem e modelam o indivíduo sem estarem separadas das outras marcações. Lugones denomina esse movimento como o sistema moderno/colonial de gênero, fomentador da imposição universal não apenas do dimorfismo sexual mas também da inferiorização da geolocalização e cor de pele das sujeitas em relação aos esquemas da colonialidade do poder.

Perante a exposição dos eixos de dominação em cada área da existência pelo sistema moderno/colonial de gênero, nos deparamos na amálgama do corpo com a subjetividade. 0 termo "corpo-subjetividade" se constrói neste texto por dois anteparos: o primeiro provém da capacidade do corpo de estar no mundo. Esse fato influencia na forma como os outros agentes interagem com este corpo, influenciando diretamente na sua subjetividade; assim, sua psique é atravessada radicalmente por uma experiência vivida de sua materialidade no espaço (como o tipo de tratamento específico que um indivíduo fora das normas hegemônicas de ser e estar no mundo pode sofrer em diferentes contextos). Quanto mais disruptivo, mais atiçador do projeto de subalternização dos dissonantes. Imagine um indivíduo identificado e atualizado como uma travesti negra se deparando com uma passeata em que os integrantes buscam manter as crenças e convicções da ideia de uma família embasada na heterossexualidade e na gestação em nome da prole. 0 corpo-subjetividade então é diretamente afetado pelo desejo (ou a falta dele) de estar ali ou pelo rechaço que aquela pessoa pode receber em sua interação com o mundo.

Mesmo na virtualidade da internet, sem o espetáculo das imagens em si mediando a relação, encontramos as expectativas envoltas nos discursos hegemônicos limitadores. Ocasionalmente, essas falas são dissonantes e subversivas, por vezes 
indiferentes, e em parte dos momentos compostas de camadas contagiadas por todos esses elementos.

Assim, o corpo-subjetividade formado pela sujeita na relação e o que é esperado dela pelo interlocutor têm o seguinte movimento pendular: a subjetividade apresentada através do diálogo não acompanha o corpo imaginado pelo desejo do parceiro; antes de se identificar como negra, há o desacoplamento de sua subjetividade e sua materialidade pelo seu interlocutor. No momento de identificação, o desapontamento do usuário está na incapacidade de aceitar que a subjetividade expressada através das mensagens está atrelada a um corpo negro. 0 poeta senegalês Léopold Senghor, em seu poema Homem de cor, rememorado na antologia de vicissitudes de Eduardo Galeano (2015, p. 275), discorre sobre o agenciamento do corpo-subjetividade branco e a irredutibilidade atrelada ao corpo-subjetividade negro:

Querido irmão branco:

Quando nasci, era negro.

Quando cresci, era negro.

Quando o sol bate, sou negro.

Quando estou doente, sou negro

Quando morrer, serei negro.

E enquanto isso, você:

Quando nasceu, era rosado.

Quando cresceu, foi branco.

Quando o sol bate, você é vermelho.

Quando sente frio, é azul.

Quando sente medo, éverde.

Quando está doente, é amarelo.

Quando morrer, você será cinzento.

Então qual de nós dois é um homem de cor? 
O poema de Senghor se dá na reiteração de uma uniformidade no conceito de negritude, atualizada como a amálgama da consciência do corpo-subjetividade negro no mundo. A historicidade da etnia negra e as relações que se desenrolam são contempladas no poema e implicam na isonomia do corpo negro perante as obstruções de sua história. Em outras palavras, neste primeiro sentido, Senghor rebate a redutibilidade do negro com a integridade da negritude. Fanon em Pele Negra Máscaras Brancas (2008) exprime esse sentido paradoxal do esquema corporal do negro no mundo:

\begin{abstract}
No mundo branco, o homem de cor encontra dificuldades na elaboração de seu esquema corporal. 0 conhecimento do corpo é unicamente uma atividade de negação. É um conhecimento em terceira pessoa. Em torno do corpo reina uma atmosfera densa de incertezas. Sei que, se quiser fumar, terei de estender o braço direito e pegar o pacote de cigarros que se encontra na outra extremidade da mesa. Os fósforos estão na gaveta da esquerda, é preciso recuar um pouco. Faço todos esses gestos não por hábito, mas por um conhecimento implícito. Lenta construção de meu eu enquanto corpo, no seio de um mundo espacial e temporal, tal parece ser o esquema. Este não se impõe a mim, é mais uma estruturação definitiva do eu e do mundo - definitiva, pois entre meu corpo e o mundo se estabelece uma dialética efetiva (p.104).
\end{abstract}

O conhecimento implícito de Fanon é saber que sua vida foi definida por postulados de hierarquização dos humanos antes da conscientização de suas potências como sujeito. $\mathrm{O}$ autor mais à frente segreda ao leitor: "Queria simplesmente ser um homem entre outros homens. Gostaria de ter chegado puro e jovem em um mundo nosso, ajudando a edificá-lo conjuntamente." (2008, p. 106). O filósofo parte da intervenção do seu corpo-subjetividade no mundo para explicitar a amputação operada pela inflexibilidade perante o negro que Senghor aponta em seu poema, em uma vontade de ocupação de um lado neutro, geral e universal de estar no mundo, ou seja, o lugar que a branquidade ${ }^{15}$ criou e ocupou

A perspicácia de Fanon para traduzir o movimento dialético do seu Eu na grade cultural, social e sensorial da época nos faz retornar às experiências da nossa sujeita. Existe nas conversas a mesma irredutibilidade do seu papel negro perante o usuário. A universalização de características femininas não-negras (ou, mais explicitamente,

${ }^{15}$ Branquidade é um sistema de poderes baseado na hierarquização entre brancos e não-brancos e as possibilidades de discriminação que podem existir no interior dessas relações. 
brancas) implicadas por alguns usuários na informação $f$ parte do desejo de decalcar sua interlocutora em uma padronização do desejo. Os moderadores das potencialidades da sujeita criam seus cortes através de uma intersubjetividade alimentada pelo sistema moderno colonial de gênero. Sendo assim, a expressão do desejo cria um engodo à experimentação de si da sujeita, que transfigura o seu corpo-subjetividade em um corpo-subjetividade moderno/colonial de gênero.

As relações momentâneas do Omegle evidenciam o que cada usuário considera como um excesso no seu imaginário particular, em que desejos infames e hegemônicos criam outros paradigmas para serem acatados. Caso os interlocutores não se enquadrem nesses anseios, a saída do chat passa a ser um caminho fácil. Na micropolítica do site, com seus atores encobertos pelo confortável manto do anonimato, a sujeita "infame" não poderá compor a ideia de sujeita que distende o desejo e o afeto de um diálogo banal, rotineiro e/ou sexual nas relações de poder entre comuns desconhecidos.

Se esse repertório cultural que modula a imaginação caminhar ao lado das abnegações racistas cujas palavras são instrumentos, vislumbraremos o mecanismo micropolítico de poder tolhendo as existências, seja no virtual ou no concreto. Retomamos a Fanon (2008) e à consciência do seu estado no mundo para exemplificar as impugnações que podem vir pela materialização da negritude nos espaços:

"Olhe o preto!... Mamãe, um preto!... Cale a boca, menino, ele vai se aborrecer! Não ligue, monsieur, ele não sabe que o senhor é tão civilizado quanto nós..." [...] No momento em que eu esquecia, perdoava e desejava apenas amar, devolviam-me, como uma bofetada em pleno rosto, minha mensagem! 0 mundo branco, o único honesto, rejeitava minha participação. De um homem exige-se uma conduta de homem; de mim, uma conduta de homem negro - ou pelo menos uma conduta de preto. Eu acenava para o mundo e o mundo amputava meu entusiasmo. Exigiam que eu me confinasse, que encolhesse ( $p$. 106-107).

Como não constatar o atravessamento que esses discursos executam nas vidas? Seria cínico ignorar as potencialidades riscadas por estas palavras. É neste conjunto de opressões e sentidos hegemônicos que a nossa sujeita se encontra. As experimentações deste corpo-subjetividade exemplificam como o sistema colonial/moderno de gênero 
caracteriza-se na concretude vivida, como a imposição da colonialidade do pensamento enraizou-se e brotou como norma no cotidiano dos corpos-subjetividades dos descendentes originários dos focos ideológicos de opressão, mas também dos descendentes dos dominados.

\title{
A mulata violão
}

No ensaio Racismo e Sexismo na Cultura Brasileira (1984), Lélia Gonzalez contemplou pontos caros a este artigo. Sua contribuição intelectual ainda se mostra atual para o simbolismo da mulher negra, não apenas no território nacional, mas mundial. A antropóloga denunciou as três vertentes de atualização das mulheres negras brasileiras na seleção do senso comum: a mulata, a mucama e a mãe-preta. Gonzalez (1984), sob a perspectiva psicanalítica, parte do apontamento do lugar da mulher negra na formação cultural brasileira e seus diferentes aspectos de rejeição e integração.

\begin{abstract}
0 mito que se trata de reencenar aqui é o da democracia racial. E é justamente no momento do rito carnavalesco que o mito é atualizado com toda a sua força simbólica. E é nesse instante que a mulher negra transforma-se única e exclusivamente na rainha, na "mulata deusa do meu samba", "que passa com graça/fazendo pirraça/fingindo inocente/tirando o sossego da gente". É nos desfiles das escolas de primeiro grupo que a vemos em sua máxima exaltação. Ali, ela perde seu anonimato e se transfigura na Cinderela do asfalto, adorada, desejada, devorada pelo olhar dos príncipes altos e loiros, vindos de terras distantes só para vê-la. Estes, por sua vez, tentam fixar sua imagem, estranhamente sedutora, em todos os seus detalhes anatômicos; e os "flashes" se sucedem, como fogos de artifício eletrônicos. E ela dá o que tem, pois sabe que amanhã estará nas páginas das revistas nacionais e internacionais, vista e admirada pelo mundo inteiro (Gonzalez, 1984, p. 228).
\end{abstract}

A violência simbólica do enquadramento da mulher negra transformada em mulata se inicia a partir de seu endeusamento não apenas no carnaval, mas em toda situação de ganho sexual. Entretanto isso se comuta em outra face. González chama atenção para o cotidiano dessas mulatas fora de suas alegorias feéricas carnavalescas, ressaltando a carga de racismo diário que reterritorializa a mulata no papel de empregada doméstica. Dessa forma, a partir dos elementos apresentados, “(...) se constata que os termos mulata e doméstica são atribuições de um mesmo sujeito. A nomeação vai depender da situação em que somos vistas" (Gonzalez, 1984, p. 228). 
Estes estigmas sobre a mulher negra existem paralelamente, tal como sua terceira face, a da mãe preta, caudatária do papel doméstico, atrelando o cuidado da casa ao zelo pelas crianças residentes da mesma. A segunda conversa virtual exposta traz o fetiche spoiled brat/maid que consideramos a epítome ilustradora das amostragem de González. Neste roleplay encontram-se as três categorias descritas pela autora: a mulata sensual, que no desejo do proponente está correlacionada com a figura da brasileira internacionalmente comerciável e desprovida economicamente, culminando em seu cargo de empregada doméstica (maid) e a mãe preta, já que, na fantasia, há uma tensão maternal sendo embaralhada pelos dois outros papéis, pois a idade do objeto de desejo é mais avançada em comparação com o parceiro, atualizado como um brat, um menino mimado.

A propósito, o termo mulata também toca no limite do que pode ser transformado em objeto de desejo, manipulado pela colonialidade dos corpos, que infere na exotização da negra assinalando-a como "mulata", uma negra de pele mais clara. As variações de melanina dentre os arquétipos de mulheres negras são acompanhadas das intenções de suas parcerias, podendo variar entre a exotização pura, aversão ou companheirismo/empatia ${ }^{16}$. Neste caso, tivemos a exotização; nas seções anteriores deste artigo, entretanto, amostras de aversão foram exemplificadas. Em relação aos sentimentos de companheirismo/empatia, as interações que chegaram a um estado efetivo de troca de mensagens não suscitaram essas emoções, tangenciando apenas em uma finalidade sexual expressada pela outra parte.

16 O caso Nayara Justino joga a luz da compreensão sobre essa passagem. Em 2014, a Rede Globo promoveu um concurso para eleger a nova Globeleza da emissora. 0 título é atrelado às vinhetas que celebram o período do carnaval e são exibidas no intervalo dos programas. A competição foi exibida durante o programa dominical noturno Fantástico, tendo Justino, a mais escura das competidoras, como ganhadora. Após assumir o cargo, o perfil da emissora nas redes sociais e o da própria Nayara receberam retaliações racistas direcionadas à escolha da mulher que desempenharia a função de Globeleza. As críticas culminaram na demissão de Justino do papel obtido no concurso sem justificativas claras. Um documentário realizado pelo jornal The Guardian apontou como causa o racismo imbricado na cultura brasileira, sinalizando a cor mais atenuada das Globelezas anteriores e a sua substituição por uma mulher mais clara, denominada culturalmente como "mulata" e que não passou por nenhum tipo de competição para assumir a posição. <http://revistaglamour.globo.com/Lifestyle/Cultura/noticia/2016/02/ex-globeleza-nayara-justino-etema-documentario-sobre-racismo-no-brasil.html> Acesso em: 09 de fev. 2018 
A compilação das reações à revelação da cor de nossa voluntária suscita um questionamento sobre a efetiva possibilidade de existência de formas inovadoras de conexão com outros em ambientes como o Omegle, um lócus aparentemente propício aos encontros para além das aparências. Com base nas conversas trocadas, essa perspectiva mostrou-se ingenuamente otimista.

\section{0 anonimato excludente}

Desprovida da capa da universalidade branca atribuída ao termo "mulher" (f), a sujeita encara o sistema moderno colonial de gênero, assim como a repetição - com diferenças - da experiência de Fanon na França - "Olhe, mamãe, um preto!" (2008, p. 106). A presença de Fanon está dada em seu simples surgimento no espaço público. Fanon chamou de "stimulus externo" as interpelações emitidas pelos transeuntes das ruas da cidade europeia que o cutucavam enquanto passava. "Sou sobredeterminado pelo exterior. Não sou escravo da 'ideia' que os outros fazem de mim, mas da minha aparição" (2008, p. 108). Roupas da mais alta hierarquia ocidental poderiam ser-lhe atribuídas, mas a alteridade radical (e racial) criada pela colonialidade do poder e pelo sistema moderno colonial de gênero, cerzidos na Europa e cultivados em suas filiais, não deixarão de atuar, realocando-o em um lugar de subalternidade.

Em nossa observação, não nos deparamos com nenhuma frase similar ao grito proferido ao filósofo; o "stimulus externo" de $f$, 36, Brazil e black é a saída brusca de cena de seu interlocutor e seu papel de empregada dentro do fetiche do outro.

No momento da declaração "eu sou negra", a sujeita comete o que Sibilia (2016, p.40) chama de sincericídio ${ }^{17}$, ao qual Fanon não precisaria recorrer, já que suas experiências são baseadas em seu corpo no espaço público concreto. 0 conhecimento situado no real do corpo generificado como feminino de pele negra aponta para o

170 neologismo foi formado para exemplificar o caso de uma adolescente australiana muito popular por sua rede social Instagram, famosa por exibir um estilo de vida de alto nível social e autocentrado no seu corpo e nas suas companhias. A autora da conta, Essena O'Neill, em um momento de estafa na sua performance, confidenciou as artimanhas utilizadas para capturar uma boa foto e toda a falsidade envolvida na exposição online em um vídeo amplamente repercutido. 
mesmo lugar, sem surpresas: sua presença, apesar de ser moldada por características amplas e gerais, recebe estímulos semelhantes aos direcionados na vida concreta, mas, dessa vez, uma dupla peculiaridade arrebata as experimentações do corpo. Os comportamentos dos parceiros não emergem de sua aparição, como no caso de Fanon, mas através do seu corpo narrado. 0 segundo fenômeno é o desconhecimento do rosto de seu interpelador, cujas palavras afetam diretamente o corpo-subjetividade da sujeita, assujeitando-a aos padrões moderno-coloniais de gênero.

É notável que a experiência de si na cultura ocidental seja feita através da linguagem. No momento que se conta, o $E u$ organiza o seu conhecimento na primeira pessoa do singular atualizando-se no e pelo poder de narrar-se. Se a narrativa de si é acompanhada de poder, poder-se-ia encontrar uma brecha para um agenciamento do Eu ao narrar-se perante os outros, uma centelha criativa que atuaria de modo a dar certo alívio ao assujeitamento de 36, f, Brazil. Entretanto, Sibilia (2016) explicita as limitações das possibilidades criativas do sujeito que se constrói enquanto se narra:

[...] boa parte desses discursos se origina fora de si, já que os outros também nos narram. E, como se sabe, os outros não são apenas o inferno mas também costumam ser um espelho, e possuem a capacidade de afetar a própria subjetividade dos modos mais diversos. Assim, tanto o eu como seus enunciados são heterogêneos: para além de qualquer ilusão de identidade, eles sempre estarão habitados pela alteridade. Toda a comunicação requer a existência do outro, do mundo, do alheio, do não-eu, por isso todo discurso é dialógico e polifônico, inclusive os monólogos e os diários íntimos, pois a natureza é sempre intersubjetiva. Todo relato se insere num denso tecido intertextual, entremeado com infinitas narrativas e impregnado de outras vozes, e disso não estão isentas nem as mais solipsistas narrativas do eu. (p.58)

No capítulo "A experiência vivida do negro", Fanon (2008) evidencia a impossibilidade da concepção de qualquer ontologia em uma sociedade colonizada e civilizada. Pois esta parte da filosofia se afasta da existência, e é nesta instância que há a consolidação da pessoa negra, afinal "o negro não tem mais de ser negro, mas sê-lo diante do branco" (Fanon, 2008, p.104). A narrativa espelhada pela modernidade e colonialidade do pensamento exclui a possibilidade do negro ter uma existência ontológica, narrada por si mesmo e por sua história e cultura cruas, já que as máquinas capitalistas dos séculos escravistas impuseram outro sistema de referência para estes indivíduos: a cultura europeia "civilizada" e seus habitantes brancos. Citamos o filósofo 
martinicano novamente por medo de não sermos fiéis à acuidade de suas palavras, ao referir-se aos negros: "sua metafísica ou, menos pretensiosamente, seus costumes e instâncias de referência foram abolidos porque estavam em contradição com uma civilização que não conheciam e que lhes foi imposta". (Fanon 2008, p. 104)

Por fim, a hipotrofia do ser causada pelas experimentações do corposubjetividade da sujeita no Omegle se constrói por intermédio de deslocamentos e compressões que operam para encaixá-la em um modelo apresentável, pois, na sua concretude, ela está fora do desejo de muitos e puramente fetichizada por outros. Nesta conjuntura, este artigo encaminhou-se para a seguinte constatação: para uma mulher negra, brasileira, de 36 anos, o Omegle se configura como uma rede que, na potencialidade do virtual, resguarda, e por vezes atualiza, o seu anonimato excludente, causando uma inibição do narrar-se de forma muito análoga ao que acontece na materialidade da vida.

\section{Referências bibliográficas}

DAMASCENO, Alex. A interação entre estranhos no Omegle.com: sociabilidade, relacionamento e identidade. E-compós. Brasília, v.16, n.3, set./dez. 2013

FANON, Frantz. Pele Negra. Máscaras Brancas. Bahia: Editora Edufba, 2008.

FOUCAULT, Michel. A Arqueologia do Saber. Rio de Janeiro: Editora Forense Universitária, 2008.

Dits et écrits. Édition Établie sous la direction de Daniel Defert et François Ewald. Collaboration de Jacques Lagrange, Vol. I et II. Paris. Quarto Gallimard, 2001

GALEANO, Eduardo. Os Filhos dos Dias. Porto Alegre: L\&PM Editores, 2015.

GONZALEZ, Lélia. Racismo e Sexismo na Cultura Brasileira. In: Revista Ciências Sociais Hoje, Anpocs, 1984, p 223-244.

LATOUR, Bruno. Redes que a razão desconhece: laboratórios, bibliotecas, coleções. In: André Parente (ed.). Tramas da rede: novas dimensões filosóficas, estéticas e políticas da comunicação. Porto Alegre: Sulina, 2004.

LUGONES, M. Colonialidad y género. Tabula Rasa, núm. 9, págs. 73-101, 2008. QUIJANO, Aníbal. Colonialidad del Poder y Clasificación Social, Festschrift for Immanuel Wallerstein, part I, Journal of World Systems Research, V. XI:2, summer/fall, 2000. 
SIBILIA, Paula. O show do Eu: A intimidade como espetáculo. Rio de Janeiro: Ed. Contraponto, 2016. 